
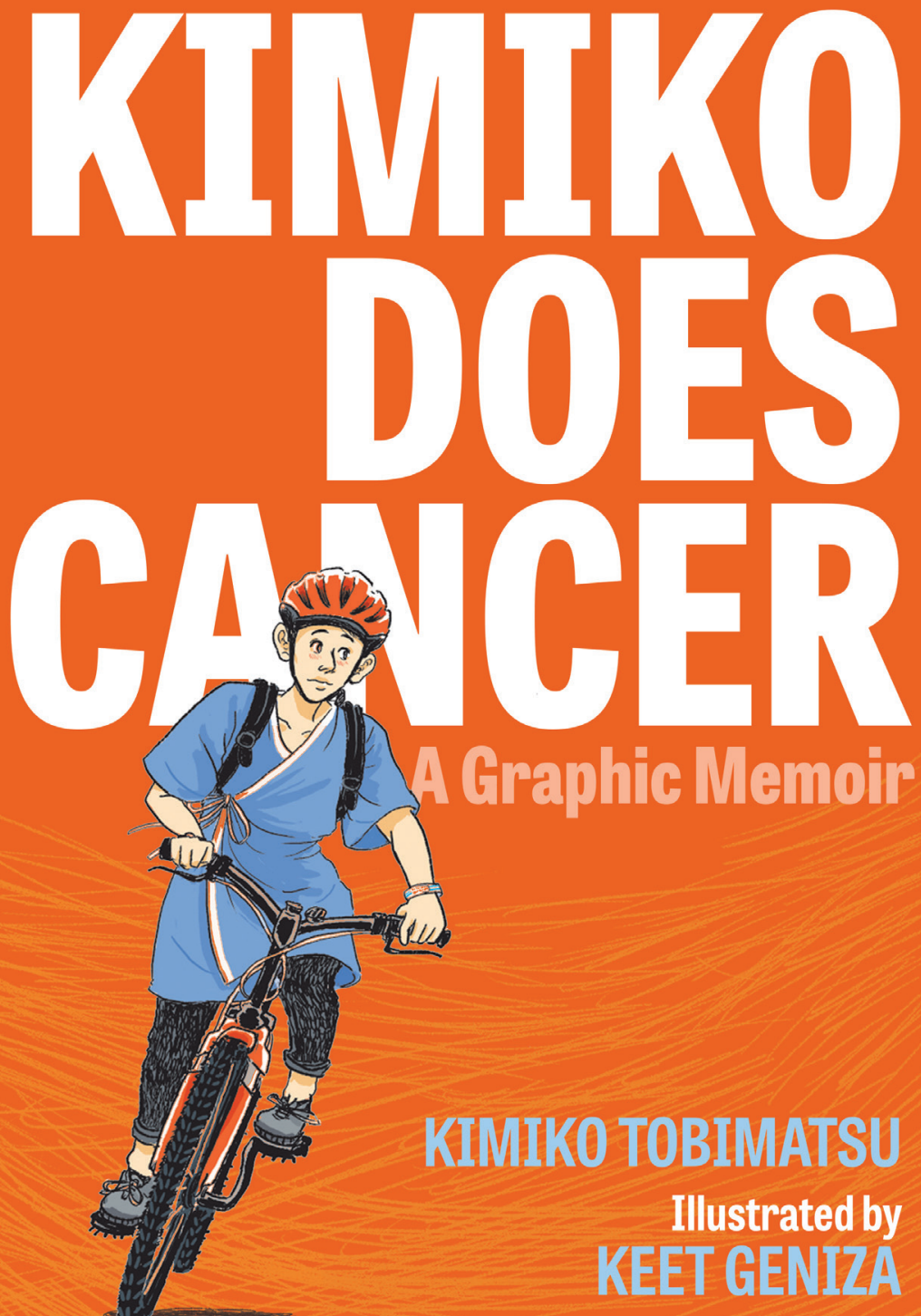

Reprinted with permission from Kimiko Does Cancer: A Graphic Memoir by Kimiko Tobimatsu and Keet Geniza (Arsenal Pulp Press, 2020). 


\section{Kimiko Does Cancer}

Lisa Folkmarson Käll in conversation with

Kimiko Tobimatsu and Keet Geniza

KIMIKO DOES CANCER is a graphic memoir written by Kimiko Tobimatsu and illustrated by Keet Geniza. The book tells the story of Kimiko's experience with breast cancer as a young, queer, mixed-race woman. Set in Toronto, Canada, Kimiko Does Cancer seeks to upend the traditional cancer narrative, confronting issues such as dating while in induced menopause, navigating work and treatment, and talking to wellmeaning friends, health care professionals, and other cancer survivors.

In the interview below, Lisa Folkmarson Käll talks with Kimiko and Keet about their three-year long collaboration on the project, their hopes for it, the importance of representation and the difficulties of dealing with vulnerability.

Page references in the text are to Kimiko Tobimatsu and Keet Geniza's Kimiko Does Cancer: A Graphic Memoir (Vancouver: Arsenal Pulp Press, 2020).

Lisa: How did this project that has now resulted in your amazing book Kimiko Does Cancer get started? 
Kimiko: The book didn't start as a book project but as something much smaller, and then it developed and grew into a book as Keet and I worked together. Originally it was only twenty or so pages, and what I highlighted reflected interactions with doctors and the cancer community that really stood out to me. Something would happen and I'd think “This is bizarre, I want to write it down". I spent a few months doodling and trying to work through my frustrations with drawing, but it didn't take long before I gave up on the idea of learning how to draw. At the same time, I was realizing that there could be a wider audience for the project and in order to give it the best chance of success, I needed to work with an illustrator who knew what they were doing, and that's how Keet got into the project. I started asking around about queer women of colour illustrators. When I got Keet's name and saw her artistic style and the fact that she was queer and Asian, it seemed like a perfect match.

I really came into this story thinking that there are not enough stories out there right now that are talking about queerness and the medical system and how that affects our care. I wanted to reduce that gap and broaden the scope of representation, not only in terms of the stories that are told but also who tells them. When I looked for an illustrator, I also knew that a queer person was more likely to understand what was difficult about my interactions with the medical system and cancer community. Plus, in terms of my relationships with other people and my friends and partners, having a queer illustrator meant I wouldn't have to explain, you know, queer culture. And I think this is reflected in the way Keet illustrated the story. The fashion, for instance - I keep coming back to this because I think this is so amazing - Keet understands queer fashion. There are all these little details in there, these patterns and textures and things that she just got. Drawing the other queer characters in the book came naturally to her.

Keet: I actually walked into the project thinking it was a regular commission, and then it developed into a three-year long collaborative endeavour. It was going to be just a zine, and then it turned into a fulllength comic. When I came into the story, there were many emotional 
nuances and expressions that I understood and empathized with. I think I came at it from a mostly intuitive or emotional understanding. There were moments when I was helping Kimiko write the book that I would remind her of the vulnerability inherent to queer writing.

Lisa: What were some of the things that really stood out to you in your interactions with doctors? What were some of these bizarre moments?

Kimiko: The interaction with my plastic surgeon and the conversations with her around breast reconstruction definitely stood out as bizarre to me. She asked me if I wanted her to enlarge my breasts at the same time that she did the reconstruction. That was just so outside of my norm or my life circle. I had actually come from the perspective that losing my breasts wouldn't be the worst thing that could happen. I wondered if I might in fact like the look and how it might enable me to play with gender a bit more.

Or, for instance, in relation to the research I was part of, when I realized that I was now in this focus group of all, or seemingly all, straight women and no one was bringing up other perspectives. That was one thing that really stood out to me. I think stepping into a much straighter world, there were tangible examples of me being a fish out of water, like those two examples, and then also just this intangible feeling of, you know, these aren't my people.

Lisa: I'm thinking also of the rather long passage in the book where you talk about the option to have kids and the discussion around deciding whether to harvest and freeze your eggs. In the book, you describe how you were encouraged to consider family planning and you write that cancer pushed the decision to harvest your eggs before you were ready for it. You describe it as an awful experience but still something you don't regret. Was there ever any discussion of other possibilities of having kids, outside of this process of egg-freezing-for-future-babymaking? 
Kimiko: For a while I was going back to see my fertility doctor every year and every time I came back she would ask me "Now are you ready?" There was definitely pressure to get started. But at the same time, she would quip that I at least had two uteruses to choose from. I understood her to be acknowledging that carrying decisions are different for queers. It certainly didn't go beyond that, though.

My fertility doctor wasn't talking about why I might not want to have kids at all and why that was just as legitimate a choice. She wasn't talking about how support networks for queer families can look different, that donor parents might be involved in care. Adoption wasn't raised either.

The discussion with the fertility doctor kind of reminds me of the language of "love is love" used in some queer communities, or, actually, it's maybe even more straight people using it to say "This is an example of why we accept queer culture, love is love". The implication is that it's all the same, we're just transplanting a woman for the man but everything else is the same. We're tolerable because we're the same. It's a very depoliticizing message to say that your queerness doesn't transcend more than who you have sex with. But certainly my queer politic is that my sexuality affects much more than literal sex and we shouldn't be mimicking heteronormative relationships and expectations around having kids.

I have considered at various points whether I should just get a hysterectomy instead of staying on the menopause drugs. Maybe if I have a hysterectomy my body will be able to adjust in a different way than the meds kind of artificially regulating my body. But the doctors are just so very cautious. They tell me to wait a few more years, let's see what happens, you might want to have kids. There's no distinction drawn between raising kids and physically birthing kids. I'm not fully decided on the former but I'm quite certain about the latter. I do get why doctors would take a cautious approach, but I think it's beyond just caution, it's informed by this heteronormative assumption that women all want to birth biological kids. 
Lisa: I'm thinking that there is caution around closing certain doors but that there are at the same time other doors that are never even opened and hidden behind naturalized normative structures. In the book, you highlight how normative mainstream narratives of breast cancer are: they're white, heteronormative, feminized and apolitical. And they are, as you point out, most of the time success stories, stories of survival and heroic overcoming of adversity and not about for instance feelings of failure or of experiencing ongoing disability. You write that "the peppiness seemed to gloss over the way cancer affected people differently based on race and class" (39). While the story you tell is far from the mainstream cancer narrative of heroic overcoming of adversity, it is still a story of survival and I think rather heroic, though in a sort of low key, unfussy way. How did you relate to mainstream cancer narratives and the discourse of heroic survival as you wrote your story, also of survival?

Kimiko: In the epilogue I'm partly struggling with that. I've been pushing back against this simplistic idea that "I fought cancer, came out stronger, everything's great". Largely, the story I tell is a reaction against that messaging and not feeling a part of it. I don't want to paint it all with the same brush though. I mean, I was going to support groups and I gained a lot through those support networks. While I'm pushing back against a certain discourse, I do have to acknowledge the fact that through this experience and my processing of it and going to therapy, I am more self-aware, I have better boundaries and I'm better able to express myself.

Basically, I hope that I can speak to a maybe more nuanced way to complicate that typical story of, you know, "Now it's all roses". And, while I'm coming to it from a queer perspective, I do think straight people can also benefit from the shift in perspective.

There are still so many stories that are not represented. I think of metastatic breast cancer for instance. It's really not talked about very much because we're choosing to focus on these glossier, more heroic stories, but then we're denying people their experiences. 
Lisa: Do you think the graphic medium itself does something in relation to the queering of a normative discourse and the opening up of possibilities to relate to the story?

Keet: It really does contribute that the story is illustrated and not merely written. On one level, it has to do with representation, about seeing yourself or bits of yourself in the narrative. So, a queer person who had cancer when they were young could relate to the book. And with the story illustrated in a comic format, I think it extends its relatability to the wider world. People love imagery, the world we live in is a very image-based world. Images are bridges to further understanding. Images and comics are a language that people can easily access, both in terms of creating and in terms of taking it in by reading.

Kimiko: On the point of representation, a couple of queer people have commented about how much they love the sex scene in the book. I think it's about really getting to see ourselves in this very tangible way: it's not only the written word, it's "Oh yeah, there we are". Even in movies, I'm always looking, and then thinking, why did you stop at just the kiss? So, to actually see parts of a sex scene drawn out, I think is very valuable.

Our book is quite different from what's out there right now when it comes to breast cancer in comics. Perhaps the two most prominent examples are Jennifer Hayden's graphic memoir and cancer narrative The Story of My Tits (2015) and Marisa Acocella Marchetto's Cancer Vixen: A True Story (2009). Both of those books are told from the perspective of straight women and particularly Cancer Vixen is about this very feminine woman, and her relationship with a man figures prominently in it. I think it's more in informal writing, in different networks and blogs, that we're seeing more diverse representation.

Lisa: The portrayal of the sex scene is very intimate and also an exposure of vulnerability that I see as really characterizing the book as a whole. Did you talk about vulnerability throughout the process of working on this project? 


\section{Kimiko \& Keet: Yes!}

Keet: We had many conversations about vulnerability. It's one of the reasons the book is longer. We picked up and left behind a lot of material along the way. That involved a lot of digging on both our ends. On my end, I definitely had to grapple with the way I create with another person, which is a very personal process and definitely tied to a lot of my vulnerabilities as a person and artist.

Kimiko: You know, I've been asked how I worked up the nerve to kind of start this story and share it. It's funny because the original version of it didn't feel scary. It was just these witty descriptions of what happened. Like Keet said, we thought we would make something much smaller. It was through the process of working with Keet that the vulnerabilities came out and the fears associated with it. It didn't start that way at all. Keet asked me to reflect and expand and go beyond the basics that I had laid out and that was difficult.

The first version that I wrote was the safest one. It talked about my relationship to people who were, essentially, strangers: doctors, people I met in support groups, the cancer community more broadly. But what Keet asked me to do was to reflect on my interactions with people much closer to me. One of the big struggles was around revealing things in the book that I hadn't yet shared with the people it pertained to or, in some cases, with anyone. To be honest about the experience, I realized I had to talk to the people who were in the book. That was hard. One thing I decided to do in terms of creating comfort was to write under a pen name. I wanted to create a bit of distance between my personal life and what my professional clients might be able to easily find on the internet. But as the book is coming out and as people are reading it around me, I am a little bit nervous about the exposure. These are conversations I haven't had with many people and now they're seeing my inner thoughts and my insecurities.

Keet: I knew I was asking Kimiko for a lot and I would sometimes wonder whether she was leaving something out. She told me it wasn't her nature 
to share deeply and it was one of the things that I struggled with. I had to remind myself that sometimes people have reservations about sharing. I wanted to handle it as gently as possible. I had moments where I felt a bit guilty, where I thought maybe I was pushing her to share more than she was comfortable with. But I was also thinking, what about the art?

Kimiko: I actually remember a conversation where I was struggling to write out my emotions and Keet said something like, "Art is vulnerability". I groaned. I had never worked with an artist on a project like this and I had some learning to do.

Keet: This idea of art as vulnerability is reflected in my entire art practice. When I'm creating stories, I'm always thinking about the act of sharpening a knife - cutting through whatever issue or emotion there is and revealing it wide open. So, art and storytelling are a way to get at the root of the matter. It can reflect whatever vulnerabilities you might discover through the process of making it. Or not. Sometimes you get exposed to parts of yourself that you might be unaware of, which might suddenly influence the work to such an extent that it goes in an entirely different direction. Art could serve as a medium towards vulnerability but also as a tool to dig deeper into one's soul or psyche or the meaning of certain experiences. It is more than the image or form that it takes. It's also in the thoughts that inform what you decide to put on the page, even when they are not as obvious.

Kimiko: Throughout the work, Keet was respectful of my boundaries and I think her questions were really helpful, both personally, as I reflected on my experience, and also in creating the final product. It just required that I check in with myself regularly to avoid a situation of regret and over disclosure. I needed to make sure that as I was answering Keet's questions, I was also evaluating whether I still felt comfortable with how much was going into the book. There have been moments in my life where I've over shared and regretted it. This, fortunately, isn't one of them. I don't hold any regrets about what's been included. 
I was also keeping in mind what $\mathrm{I}$, as a reader, like to see and that is vulnerability. So, I think that while including, for instance, the sex scene, involves some awkwardness and I don't love the idea of my family or colleagues reading that, I'm also aware of how important it is to include those really embarrassing and also representative images. I think delving into those more private topics makes the book more relatable.

Lisa: How was your working through your experience as you wrote the story different from living through it?

Kimiko: I think in the experience of going through cancer I wasn't emotionally absorbing it. My MO is to keep moving along and try not to let things stall me. I kept my job through much of radiation, took only a little bit of time off around my surgery and pretty much just kept chugging along.

My therapist talks to me about our first session which was at the end of radiation. Her expertise is in trauma and when I arrived, I said "I'm not sure I'm the kind of patient that you want to see, I don't necessarily think I've gone through trauma". She responded "What you went through is trauma and your tendency is so much towards belittling your experiences that you don't think of it as trauma". I think there's a variety of reasons for this, you know. I have privilege and I try to acknowledge that. My going through cancer looks a lot different than, for instance, a black woman going through cancer. But maybe I take that societal reality too far and use it to write off the difficulties I'm going through. So, I think the initial moving through cancer was a lot different than through writing the book and working with Keet. She pushed me to look at how the experience impacted me and that is an uncomfortable examination but one that's very fruitful.

Lisa: The way you talk about the project it really appears as a joint project, even though it's Kimiko's own personal story. Can you say more about the collaboration between the two of you? 


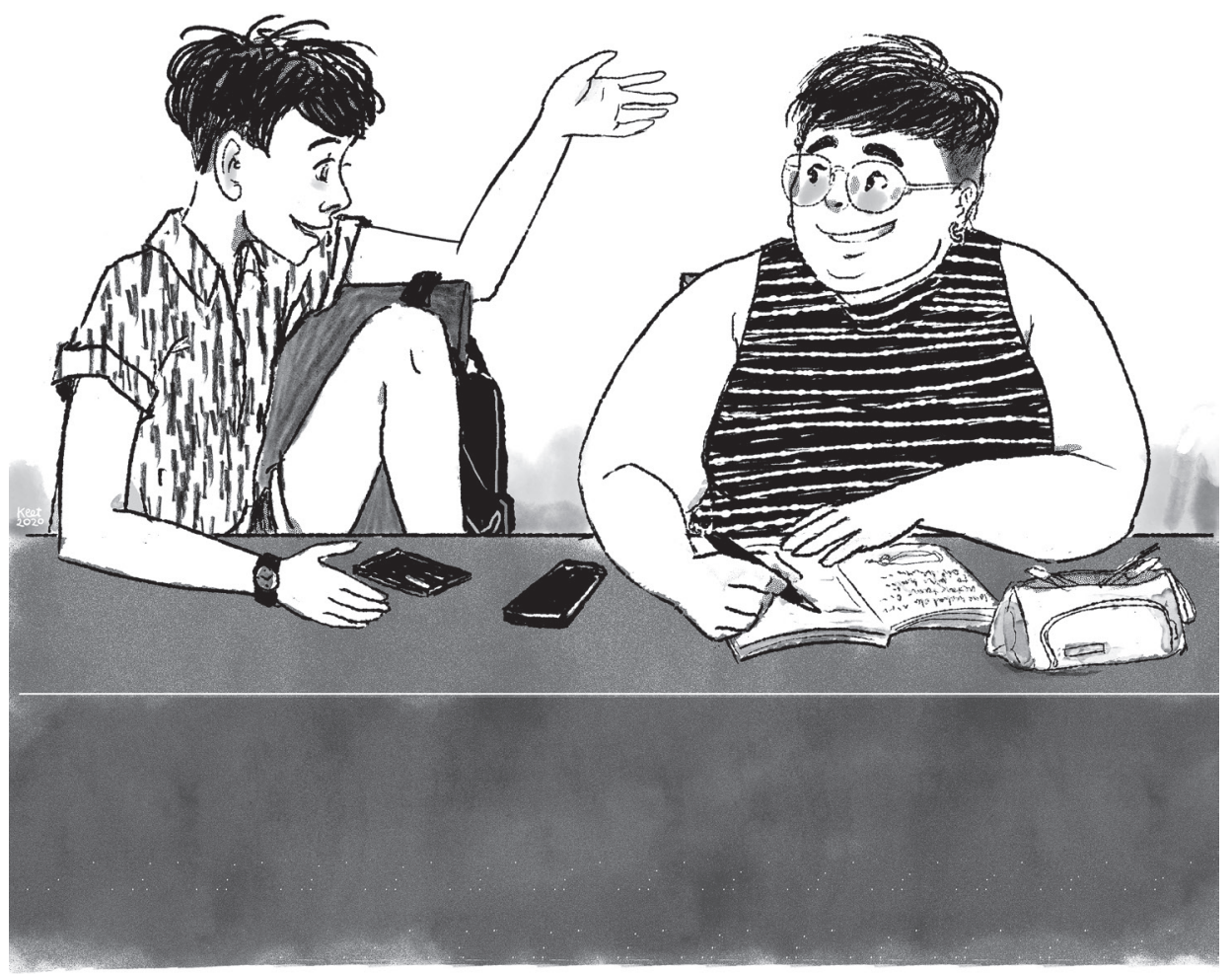

Image by Keet Geniza. Printed with permission. 
Keet: It's a super joint project! The way we wrote the book was a very joint endeavour. We both thought that it was going to be a zine. And even though it turned into a longer book, it's not like I was passively watching that happen.

Kimiko: Keet was the puppeteer! In the best way.

Keet: When Kimiko showed her draft, I was already asking questions in my head. I was already interrogating the text in my head, kind of asking more of it. I asked if Kimiko was okay with me helping her expand the story, and that's when it really became a conversation between us. You know, there are many people who write a whole script and then expect an illustrator to draw it with no further questions asked, but that was not the case here. We really worked closely together for the duration of the project. However, if Kimiko had written the whole book by herself and just handed it off to me to illustrate, I would have still been engaged in the act of interpretation. In a way, I am also writing the story through illustrating it, interpreting the events in the story with my own experience and subjectivity, which Kimiko could then respond to. No matter how you look at it, it's still a joint endeavour. There were moments when Kimiko wanted things to look a certain way and I would sometimes argue with her about it - it's those little debates and decisions that made it a joint thing rather than just a job. I had a lot to discover about what a collaboration like this could look like and I feel lucky that Kimiko was willing to work with me in such a collaborative way. We were very equal when we were working together.

Kimiko: We sometimes had different ideas about what we wanted, but when we talked it out, we figured it out. There were also things we learned about each other's processes as we went along. Like when we were editing, I asked for some changes after Keet had inked the pages. She told me that it was hard to make changes at such a late stage because she'd put so much time into the page by that point. Not coming from an 
illustration background, it was helpful for me to understand her process and at what point she needed the final version.

Keet: One section that was particularly contentious is the one where Kimiko talks about her relationship with her mom. She was also having simultaneous conversations with her family while writing that section, so that became extra challenging because it's basically a livestream of what's happening in her life that we were immediately writing about. The conversations were particularly emotional, so her wording changed many times and facial expressions had to be really fine-tuned and stuff like that.

There were moments when it was just very emotionally exhausting. I had already accepted that as part of the whole process of creating so I was all for that, but it was exhausting because there were also other things happening in my life. Also, we worked on the book for three years. I knew that graphic novels and memoirs are drawing marathons - you don't really sit at it and expect it to get done in a day - and that played into the sense of exhaustion, too. I also tend to get too emotionally involved in the work, so in some sense I kind of lived in the story as well. I was really engaged with it. It's not as if I wasn't aware that the work was getting longer since I was the one pushing Kimiko to tell more of her story.

This was also my first long-term comic project. We didn't even have an end date at first. As it went along, I had to deal with my own boundaries as well as my doubts about whether I could pull it off. I knew I could do it, but could I do it for so long? I had never been tested in that way before. I remember the first time I felt burned out was when I realized that we needed an editor. That was a big lesson for me in drawing a boundary around work. As much as I was invested in the book, it was important that I found a limit to what I was willing to handle. It was also a learning experience in vocalizing what I need and taught me that maybe I should ask for what I need more often because maybe I'll get it! Having an editor didn't really influence the story we were trying to tell. It was more about keeping the future reader in mind, keeping focused on the heart of what's going on in the story. 
Kimiko: I was really glad Keet suggested an editor when she did. We were so deep into the book that it was helpful to get a fresh pair of eyes. There were hanging pieces of narrative and gaps because of how the story had evolved. Tara-Michelle Ziniuk, our editor before we went to the publisher, was able to catch those things.

We had also shown the story to an editor at another publishing company before going with Arsenal Pulp Press, and when she looked at the manuscript, she suggested some changes in the construction of the story. Her suggestion was to start with the moment of finding the lump, whereas we had originally started with the background of where I was in my life more generally during that time period. Her feedback was essentially that no one really likes their job, everyone has relationship issues, so that's not a captivating enough opening. Instead, we should start with finding the lump and then work the background in throughout. That was something that we wrestled with a little bit. I didn't want to sensationalize the experience. To just start with me finding the lump felt a little bit uncomfortable. But I of course also recognized what she was saying, that the first line, the first page is so important in captivating the reader. And we did end up following her suggestion. I still have some mixed feelings about it, but I've come around, mostly.

Lisa: One aspect of your story and your experience that could easily risk being sensationalized is that you were very young, only 25 years old, when you received your diagnosis. How do you think your youth shaped your experience and what role does it play in the story?

Kimiko: I think it brings in certain issues. We've talked about fertility, for instance. When you're young, where you are in your career, where you are in terms of whether you want to have a family, those are all different conversations than if you're a middle-aged or older woman getting breast cancer. There are life stage factors that come into focus in different ways. There are many ways in which my experience looked different because I was young and that was part of my also not feeling represented in the mainstream narratives. I just couldn't connect as 
much and I didn't feel like people were answering the types of questions that I had.

Particularly as a young person, prior to cancer, I was also operating with a perception of a certain amount of invincibility. Now it's been five and a half years but you know, at 25, other than a few sports injuries, my body was more or less doing what I asked of it. To have something very significant impede that, but also to have that thing come from within my body, made my body not feel so safe anymore and raised a lot of questions. How long had the lump been there? Was it really fast, was it slow growing? Had it been there for a year? I had a very real sense of not knowing what was happening inside me and wondering if there could be other things happening that I didn't and wouldn't know about. I really became aware of my body as something that could act outside of my will, independent of my wishes.

Lisa: Finally, what are your hopes for the book?

Kimiko: I hope to expand the image that we have of who a cancer patient is. I hope to resonate with other queers and other folks of colour who are young and have had cancer. But I also do hope that other people can find linkages to it. I think there's a variety of ways in which people can connect to bits of it. We kind of have that in our dedication, to our fellow sick queers. We're not thinking only about cancer here, both of us have medical issues that we deal with and we hope that other queers who are dealing with chronic illness or other issues will be able to relate.

And, I also hope that artistically, aesthetically, the book gets the credit it should get.

Keet: I hope the book reaches unexpected audiences. You hear so many stories about cancer but a lot of them end in death. For me, when I was working on the book, I was thinking a lot about my dad who died from cancer. I'm glad I got to do a story about someone who actually lived through cancer. I hope that people who live through cancer and are young, that they find a comfort, something positive, in this 
story. I also hope that readers who connect with the book will consider telling their own story. For me, the purpose of art has always been to move people to make their own things. That's my bigger purpose in choosing to do work as an illustrator, as an artist, to tell a story in the hope that someone might hear it and that it will encourage them to tell their own story. I hope to see more books about young queers of colour with cancer.

кıмıко тов мматsu is the author of Kimiko Does Cancer (Arsenal Pulp Press 2020), a graphic memoir about her experience navigating breast cancer as a young, queer, mixed-race woman. By day, Kimiko is an employment and human rights lawyer, as well as owner of Kimiko and Co., an online greeting card and stationery business. Kimiko was born and raised in Toronto, Canada, where she still lives with her partner and dog. Kimiko Does Cancer is her first book.

KEET GENIZA is an illustrator and comic artist. Born and raised in Manila, she moved to Toronto in 2006 and has since immersed herself in zines and comics as a way to document her struggles as a queer immigrant woman of colour. Kimiko Does Cancer (Arsenal Pulp Press 2020 ) is her first book. Keet can be found on makeshiftlove.com

LISA FOLKMARSON KÄLL is associate professor of Gender Studies and Philosophy at Stockholm University, Sweden. Her work is primarily in feminist phenomenology, focusing on questions concerning embodied subjectivity, intersubjectivity and otherness. Käll is the editor of Bodies, Boundaries and Vulnerabilities: Interrogating Social, Cultural and Political Aspects of Embodiment (Springer 2015) and Dimensions of Pain (Routledge 2013) and coeditor of Feminist Phenomenology and Medicine (SUNY Press 2014). 